\title{
Biology and Genetics of PrP Prion Strains
}

\author{
Sina Ghaemmaghami \\ Department of Biology, University of Rochester, Rochester, New York 14627 \\ Correspondence: sghaemma@bio.rochester.edu
}

Prion diseases are a group of fatal neurodegenerative disorders caused by the misfolding of the cellular prion protein $\left(\mathrm{PrP}^{\mathrm{C}}\right)$ into a pathogenic conformation $\left(\mathrm{PrP}^{\mathrm{SC}}\right)$. $\mathrm{PrP}^{\mathrm{SC}}$ is capable of folding into multiple self-replicating prion strains that produce phenotypically distinct neurological disorders. Evidence suggests that the structural heterogeneity of $\mathrm{PrP}^{\mathrm{Sc}}$ is the molecular basis of strain-specific prion properties. The self-templating of $\mathrm{PrP}^{\mathrm{Sc}}$ typically ensures that prion strains breed true upon passage. However, prion strains also have the capacity to conformationally transform to maximize their rate of replication in a given environment. Here, we provide an overview of the prion-strain phenomenon and describe the role of strain adaptation in drug resistance. We also describe recent evidence that shows the presence of distinct conformational strains in other neurodegenerative disorders.

$T^{\mathrm{h}}$ he term "prion disease" has historically been used to denote a group of fatal neurodegenerative diseases caused by misfolding of the prion protein (PrP) (Prusiner 1982, 2001, 2013; Colby and Prusiner 2011). These disorders occur in a number of mammals and include Creutzfeldt-Jakob disease (CJD) in humans, bovine spongiform encephalopathy (BSE) in cattle, scrapie in sheep, and chronic wasting disease (CWD) in cervids. A key feature in the etiology of these diseases is the self-templating and propagation of pathogenic conformations of PrP. Although the phenomenon of templated propagation was initially described for PrP-based prion diseases, recent experiments have indicated that aggregates of proteins causing other common neurodegenerative disorders can also stimulate the formation of pathogenic protein conformations in vivo (Meyer-Luehmann et al. 2006; Kordower et al. 2008; Clavaguera et al. 2009; Desplats et al. 2009; Eisele et al.
2009; Frost et al. 2009; Ren et al. 2009; Prusiner 2012). Thus, the term "prion disease" can now be more broadly applied to a range of common neurodegenerative disorders, including $\mathrm{Alz}$ heimer's (AD), Parkinson's (PD), and Huntington's diseases.

Many features associated with the propagation of PrP-based prions, including templated seeding and cell-to-cell transmission, have now been observed in non-PrP prions. Another important property of classical PrP prions that has recently been shown in $\mathrm{AD}$ and $\mathrm{PD}$ is the occurrence of distinct phenotypic strains with unique conformational and biochemical properties (Prusiner 2013; Le et al. 2014; Stohr et al. 2014; Watts et al. 2014; Morales et al. 2015). In this review, we provide an overview of the prion-strain phenomenon and outline recent evidence that suggests that distinct conformational strains are also present in $\mathrm{AD}$ and $\mathrm{PD}$. We will also describe the ramifications of the strain

Editor: Stanley B. Prusiner

Additional Perspectives on Prion Diseases available at www.perspectivesinmedicine.org

Copyright (C) 2017 Cold Spring Harbor Laboratory Press; all rights reserved; doi: 10.1101/cshperspect.a026922 Cite this article as Cold Spring Harb Perspect Med 2017;7:a026922 
phenomenon for understanding the pathology of neurodegenerative disorders and the development of effective therapeutics.

\section{THE PRION-STRAIN PHENOMENON}

The neuropathological features of PrP-based prion diseases are thought to be initiated by misfolding of endogenous cellular $\operatorname{PrP}\left(\mathrm{PrP}^{\mathrm{C}}\right)$ into a disease-associated infectious aggregate $\left(\mathrm{PrP}^{\mathrm{Sc}}\right)$. This conversion can occur spontaneously, it can be induced by the presence of genetic mutations in the gene encoding $\mathrm{PrP}^{\mathrm{C}}$, or it can be incurred by intake of $\mathrm{PrP}^{\mathrm{Sc}}$ from outside sources. These three modes of origination account for the sporadic, genetic, and infectious forms of PrP-based prion diseases, respectively. The ability of $\mathrm{PrP}^{\mathrm{Sc}}$ to act as an infectious particle is due to its capacity to stimulate its own creation in a chain reaction that uses natural $\operatorname{PrP}^{\mathrm{C}}$ as a substrate (a process that is often referred to as "templating" or "seeding"). Once the conversion process is initiated, the subsequent formation of $\mathrm{PrP}^{\mathrm{Sc}}$ occurs with exponential kinetics, resulting in the accumulation of a conformationally heterogeneous population of prion aggregates in infected tissues (Colby and Prusiner 2011; Prusiner 2013).

The strain phenomenon is a concept that was initially invoked to describe the ability of prion diseases to show multiple distinguishable phenotypes. At first, the existence of prion strains was thought to be at odds with the protein-only hypothesis, as it was unclear how the misfolding of a single protein could result in multiple and diverse disease outcomes (Soto and Castilla 2004). However, it is now known that variations in phenotypic features of prion strains can be accounted for by heterogeneities in the structural and biochemical features of $\mathrm{PrP}^{\mathrm{Sc}}$ (Bessen et al. 1995; Telling et al. 1996; Tanaka et al. 2004; Morales et al. 2007). Thus, the ability of a single PrP polypeptide chain to misfold into multiple conformations accounts for the prevalence of multiple infectious states with distinguishable disease phenotypes.

The prion-strain phenomenon was first described for scrapie when it was shown that the infectious agent could be propagated in goats as multiple phenotypically distinct entities (Pattison and Jones 1967; Dickinson and Meikle 1969). These studies indicated that goats infected with the same batch of the scrapie inoculum could develop prion disease with two distinct clinical features, termed "scratching" and "drowsy." Subsequent studies in mice showed that animals inoculated with different scrapie strains display distinct incubation periods and histopathologies, and that these characteristics are propagated with fidelity on serial passage (Fraser and Dickinson 1973). These early studies distinguished prion strains in terms of phenotypic features of the disease, such as incubation times and neuropathological profiles. However, it soon became clear that the phenotypic diversity of prion strains could also be observed in terms of the biochemical and structural properties of the pathogenic agent. For example, the characterization of two biologically distinct strains of hamster-adapted transmissible mink encephalopathy (TME) prions, hyper (HY) and drowsy (DY), indicated that the protease-resistant cores of their corresponding $\mathrm{PrP}^{\mathrm{Sc}}$ structures differed in electrophoretic mobility in denaturing gels (Bessen and Marsh 1992). This shift in mobility suggested that different prion strains have different three-dimensional conformations that expose different parts of the structure to proteases.

Other lines of evidence for the prion-strain concept came from studies of human prion diseases. Fatal familial insomnia (FFI) is a genetic prion disease caused by a mutation of an aspartic acid to an asparagine at position 178 of PrP (D178N) (Goldfarb et al. 1992; Medori et al. 1992; Monari et al. 1994). $\operatorname{PrP}^{\mathrm{Sc}}$ aggregates associated with FFI were shown to have different electrophoretic mobility when compared with sporadic CJD (sCJD). Furthermore, it was shown that an $\mathrm{M} / \mathrm{V}$ polymorphic mutation at position 129 of $\mathrm{PrP}$ modulates the effects of the $\mathrm{D} 178 \mathrm{~N}$ mutation on both the conformation of $\mathrm{PrP}^{\mathrm{Sc}}$ and disease phenotype. These observations led to the suggestion that differences in disease outcomes can be associated with differences in the conformation of $\operatorname{PrP}^{\mathrm{Sc}}$. Subsequent experiments showed that these strain-specific 
properties could be faithfully propagated in transgenic mice infected with human-derived inocula (Telling et al. 1996).

An important recent advance in understanding the biochemical nature of prion-strain diversity has stemmed from the creation of infectious synthetic prions formed exclusively from bacterially derived recombinant $\operatorname{PrP}$ (Legname et al. 2004, 2005; Colby et al. 2010; Makarava et al. 2010). Synthetic prion strains can be created by refolding recombinant PrP into $\beta$-sheet-rich amyloid fibrils, followed by intracerebral inoculation into mice. Passage of these synthetic strains into groups of mice results in diverse incubation times, and these properties can be faithfully propagated upon subsequent passage. Results from these studies suggest that the initial synthetic inoculum consists of multiple distinct strains that become "isolated" upon passage (Colby et al. 2009, 2010). Studies have highlighted the ability of $\operatorname{PrP}^{\mathrm{Sc}}$ to act as a structural template in directing the formation of nascent $\mathrm{PrP}^{\mathrm{Sc}}$ and have provided further evidence that prion-strain diversity is encrypted in the conformation of $\operatorname{PrP}^{\mathrm{Sc}}$.

\section{TECHNIQUES FOR BIOCHEMICAL CHARACTERIZATION OF PrP-BASED PRION STRAINS}

Due to their aggregated conformation, $\operatorname{PrP}^{\mathrm{Sc}}$ strains have structural properties that have been historically difficult to investigate at atomic resolutions. Instead, to differentiate prion strains, researchers often infer strain-specific conformational differences based on low-resolution biochemical characteristics of $\mathrm{PrP}^{\mathrm{Sc}}$. Perhaps the most frequently used method for distinguishing prion strains has been the electrophoretic mobility of $\mathrm{PrP}^{\mathrm{Sc}}$ after digestion by proteinase K (PK) (Bessen and Marsh 1992). The formation of $\mathrm{PrP}^{\mathrm{Sc}}$ results in an aggregated conformation that renders a portion of the protein resistant to proteolysis. Variations in the size of the protease-resistant core are suggestive of changes in the higher-order structure of $\mathrm{PrP}^{\mathrm{Sc}}$. Other low-resolution biochemical techniques for analysis of prion strains include determining the glycosylation pattern of $\mathrm{PrP}^{\mathrm{Sc}}$, the extent of protease resistance, and the rates of sedimentation.

The above approaches have provided convincing evidence that phenotypic differences in prion strains are due to structural differences in $\operatorname{PrP}^{\mathrm{Sc}}$. However, the low-resolution nature of these techniques has made it difficult to assess the full range of conformational strains. For example, it has been difficult to assess whether a specific $\operatorname{PrP}^{\mathrm{Sc}} \mathrm{PK}$-digested banding pattern is indicative of a single conformation or an ensemble of conformations with similarly sized protease-resistant cores. More recent biochemical techniques, including conformational dependent immunoassay (CDI) (Safar et al. 1998), differential affinities toward conjugated polymers (Sigurdson et al. 2007), propensity to infect specific cell lines (Mahal et al. 2007), and quantitative analysis of conformational stabilities (Peretz et al. 2001), have provided a higherresolution picture of strain-specific conformational properties. CDI, in particular, has been pivotal in providing the first sensitive conformation-dependent assay for detecting diverse strains. This assay quantitates the binding of antibodies to the denatured and native forms of $\mathrm{PrP}^{\mathrm{Sc}}$. Subtle structural differences between strains impacts the binding of the antibody to native $\mathrm{PrP}^{\mathrm{Sc}}$ to different extents. Thus, CDI can provide quantitative measures of binding profiles of the antibody to each strain. CDI and other high-resolution biochemical techniques have provided strong evidence that $\mathrm{PrP}^{\mathrm{Sc}}$ can potentially take on a large number of pathogenic conformations. These studies have led to the remarkable conclusion that rather than constituting a small number of discrete states, prion strains are likely composed of a continuous spectrum of conformations with potentially distinct phenotypes.

\section{RELATIONSHIP BETWEEN CONFORMATIONAL STABILITIES AND REPLICATION RATES OF PRION STRAINS}

What accounts for the ability of $\operatorname{PrP}^{\mathrm{Sc}}$ to adopt multiple, phenotypically distinct conformations? It is likely that all prion strains adopt cross- $\beta$ amyloid conformations with varying 
steric architectures (Del Mar et al. 2005; Nelson et al. 2005; Chiti and Dobson 2006; Wiltzius et al. 2009). The conformational heterogeneity of prions may thus arise from differences in the intermolecular register and packing of side chains. Subtle structural differences between strains can potentially alter biophysical properties that impact the rate of prion propagation in a given cellular environment. For example, conformational differences between strains can potentially alter the kinetics of $\mathrm{PrP}^{\mathrm{C}}-\mathrm{PrP}^{\mathrm{Sc}}$ interaction, conformational conversion, and fiber fragmentation. These differences may enable specific prion strains to more efficiently convert $\operatorname{PrP}^{\mathrm{C}}$ substrates with specific primary sequences and/or within specific cellular environments.

One specific biophysical characteristic of prion strains that has been found to strongly correlate with rates of propagation and incubation periods is conformational stability. Analysis of a large number of prion isolates indicates that the concentration of chaotrope guanidinium-hydrochloride ( $\mathrm{Gdn} . \mathrm{HCl}$ ) required to denature $\mathrm{PrP}^{\mathrm{Sc}}$ molecules is negatively correlated with incubation periods (Legname et al. 2006). One possible molecular explanation for this trend is that the denaturation curve of $\mathrm{PrP}^{\mathrm{Sc}}$ is an indicator of its ability to fragment and create additional catalytic ends for the conversion of $\operatorname{PrP}^{\mathrm{C}}$. Thus, a prion strain with lower stability has an increased tendency to become fragmented, resulting in increased rates of $\mathrm{PrP}^{\mathrm{Sc}}$ formation and shorter incubation periods. Additional support for this idea has come from studies of infectious synthetic prions created under different in vitro conditions in which the conformational stabilities of the amyloid inocula correlate with the infectivity of the prion strains induced in vivo (Colby et al. 2009).

Interestingly, a similar correlation between prion stability and propagation has been observed in yeast prion strains (Tanaka et al. 2004). In yeast Sup35 prions, the most rapidly propagating strains are amyloid fibrils, which have the highest tendency to fragment. Indeed, it has been shown that enhanced fragility of yeast prions can more than compensate for deceased templating efficiencies. Additional support for the importance of fibril brittleness in prion propagation has come from cell-free fiber formation assays where induction of fiber breakage increases rates of new fiber formation (Baskakov and Breydo 2007). Together, these data suggest that the variability in the conformational stability of prion aggregates plays a large role in dictating the rates of prion propagation and degrees of infectivity. However, it should be noted that some contrary evidence to this trend has been observed in hamsteradapted strains, suggesting that factors other than stability may contribute to the propagation rate of prion strains (Ayers et al. 2011).

\section{PRION-STRAIN ADAPTATION}

Early studies of prion strains highlighted the ability of prion strains to breed true upon serial passage. However, a number of subsequent observations have shown that prion strains are capable of altering their conformation to adapt to new hosts and environments in a process referred to as "strain adaptation." The process of strain adaptation is frequently observed when prions cross the species barrier. The transmission of prions across species is highly inefficient. Interspecies transmissions are often characterized by long incubation times and low infection rates (Kimberlin and Walker 1986; Scott et al. 1989, 1993; Prusiner et al. 1990). Evidence suggests that this species barrier is a result of incompatibilities between the conformations of the infecting prion strain and host $\operatorname{PrP}^{\mathrm{C}}$, owing in part to differences in the amino-acid sequences. However, upon repeated passage, the prion conformation changes in its new host, and the incubation period gradually shortens.

The process of prion-strain adaptation has also been observed as gradual interconversions of strains originating from the same organism (without crossing a species barrier). For example, as described above, passage of biologically cloned TME prions in hamsters results in two phenotypically distinct strains: DY and HY. The former strain has a characteristically long incubation period, whereas the latter has a short incubation period (Bessen and Marsh 1992). Upon initial infection of hamsters with cloned TME, the DY strain predominates. However, af- 
ter continuous serial passage, the HY strain gradually becomes the dominant strain (Bessen and Marsh 1992; Bartz et al. 2000; Schutt and Bartz 2008).

A similar phenomenon has been observed in mice infected with variant CJD (vCJD) strains. Transgenic mice expressing chimeric human/mouse PrP inoculated with vCJD prions can harbor two distinct strains of prions. In mice that express a mixture of the two strains, the faster replicating strain becomes dominant on continuous passage (Giles et al. 2010).

The phenomenon of strain adaptation has also been shown in synthetic $\operatorname{PrP}^{\mathrm{Sc}}$ strains upon serial transmission in mice. When amyloid fibrils formed from purified recombinant PrP are used to infect transgenic mice, the incubation periods of the resulting synthetic strains gradually shorten upon passage (Ghaemmaghami et al. 2011, 2013). This increase in infectivity is accompanied by a structural transformation of $\mathrm{PrP}^{\mathrm{Sc}}$ as indicated by a shift in the molecular mass of the protease-resistant core and a decrease in conformational stability. This process of strain adaptation is also observed when synthetic prions are propagated in cultured cell lines (Ghaemmaghami et al. 2011).

A similar phenomenon of strain adaptation has been observed in hamsters infected with synthetic prions. These animals are asymptomatic at first passage and initially accumulate $\operatorname{PrP}^{\mathrm{Sc}}$ with atypical banding patterns. However, subsequent passage leads to the appearance of typical $\operatorname{PrP}^{\mathrm{Sc}}$ (Makarava et al. 2010, 2011, 2012). Together, these studies show that prions can readily alter their conformation to maximize their rate of replication in a given cellular environment.

Most natural strains are stable and can propagate with a high degree of conformational fidelity over many rounds of passage. If prion strains are conformationally adaptable, why don't all strains gradually transform to a single optimized state upon repeated passage? The conformational landscape of a prion, shaped by the primary sequence of the prion protein, likely encompasses a large number of local energy minima that can indefinitely trap structures that are not at the global energy minimum
(Weissmann et al. 2011). According to this model, the localization of the prion conformation on the energy landscape will determine whether the strain is biologically stable or transient.

\section{THE MECHANISM OF PRION-STRAIN ADAPTATION}

What is the structural basis of prion strain diversity? Prions belong to the amyloid class of filamentous protein aggregates. As a group, amyloid fibrils are rich in $\beta$-sheet secondary structures and are formed by the noncovalent stacking of polypeptide chains aligned in a cross- $\beta$ configuration. However, the exact structural orientation of $\beta$-sheets can vary between different amyloid structures. A number of amyloid stacking arrangements have been described, including parallel in-register $\beta$-sheets, antiparallel $\beta$-sheets, and $\beta$-helices (Del Mar et al. 2005; Nelson et al. 2005; Chiti and Dobson 2006; Wiltzius et al. 2009). Additionally, the structure of the interlocking self-complementary surfaces of adjacent $\beta$-sheets can vary between different amyloids. The structural heterogeneity in conformations of amyloids is the likely basis of prion-strain diversity. It is thought that the conformational constraints of specific amyloid structures ensure that monomers being incorporated at the ends of the growing fiber conform to the unique structural features of each strain. Although the high fidelity of prion-strain replication is well documented, it is possible that deformed templating events (Makarava et al. 2012) occur in rare instances. Such events can result in a conformational alteration at the catalytic ends of a growing amyloid fiber that can be propagated in further rounds of monomer addition. Alternatively, prion strains may have the capacity to convert to structurally distinct self-templating strains in a stochastic process that is not strictly dependent on faulty monomer addition (Collinge and Clarke 2007). Thus, $\mathrm{PrP}^{\mathrm{Sc}}$ aggregates may have the ability to interconvert between different conformations that can subsequently replicate with fidelity. The constant conformational drift of replicating prions can continuously produce pools of struc- 
turally distinct self-replicating prions that can be acted upon by conformational selection.

Within a complex mixture of prion conformations, faster replicating strains are expected to increase their relative population over time. The rate of this selective process can be further amplified by the phenomenon of strain interference. Coexisting prion strains can influence the replication of each other by competing for a limited supply of resources required for amplification. As a mixture, coexisting strains are competing for the same pool of $\mathrm{PrP}^{\mathrm{C}}$ substrate and other auxiliary factors that may be required for $\mathrm{PrP}^{\mathrm{Sc}}$ formation. Adapted strains that are more effective at interacting with $\mathrm{PrP}^{\mathrm{C}}$ or other auxiliary factors may deny other strains the resources required for their propagation. The phenomenon of prion-strain interference has been described for a wide variety of prion strains (Dickinson et al. 1972; Bartz et al. 2004; Schutt and Bartz 2008; Shikiya et al. 2010). For example, infection with the HY strain of TME can be inhibited by co-inoculation with the TME DY strain. The results suggest that DY and HY can compete for a limited cellular resource. The combination of spontaneous conformational mutations and strain interference provides a potent mechanism for rapid adaptation of prion strains.

\section{PRION STRAINS AND DRUG RESISTANCE}

The availability of robust in vitro and in vivo models for prion disease has resulted in the identification of a number of small molecules that induce the clearance of $\operatorname{PrP}^{\mathrm{Sc}}$ (Trevitt and Collinge 2006; Sim 2012). However, many inhibitors of prion propagation display strain specificity and can be effective against some strains and not others (Adjou et al. 1996; Demaimay et al. 1999; Doh-ura et al. 2004; Kocisko et al. 2005; Kawasaki et al. 2007; Berry et al. 2013). This phenomenon has been observed in both cell culture and animal models of the disease. Given that the exact mechanisms of action for most antiprion compounds are incompletely understood, it has been difficult to ascertain the exact molecular basis of drug-strain specificity. For compounds that exert their effect by direct interaction with $\mathrm{PrP}^{\mathrm{Sc}}$, such strain specificity may derive from conformational differences in $\operatorname{PrP}^{\mathrm{Sc}}$ that influence the binding of the compound to the aggregate. For compounds that indirectly influence prion propagation by affecting auxiliary pathways or other cofactors, strain specificity may be indicative of the relative dependence of the propagation of a given strain on that specific pathway or cofactor.

The fact that antiprion compounds can be strain-specific and that prion strains have the ability to conformationally adapt to maximize their rates of replication has given prions the capacity to evade the actions of antiprion drugs. This drug-resistance phenomenon has recently been shown in experiments involving three drugs targeting mammalian prions: quinacrine, swainsonine, and aminothiazoles.

\section{Quinacrine}

Quinacrine's antiprion activity was initially reported by two independent studies in prioninfected neuronal cell-culture systems (DohUra et al. 2000; Korth et al. 2001). Incubation of prion-infected cells with quinacrine induces the clearance of protease-resistant $\operatorname{PrP}^{\mathrm{Sc}}$. A subsequent study using bis-acridine compounds that comprise two acridine ring scaffolds connected by a linker showed the improved potency of this class of therapeutics (May et al. 2003). Despite its promise in cell-culture models, quinacrine has not proven effective in mouse models or human clinical trials (Collins et al. 2002; Barret et al. 2003; Nakajima et al. 2004; Collinge et al. 2009; Ghaemmaghami et al. 2009; Geschwind et al. 2013). In MDR $1^{0 / 0}$ mice lacking ATP-binding cassette (ABC) transporter P-glycoprotein (Pgp), quinacrine accumulates in the brain at levels that exceed its in vitro effective concentration by a factor of 100 (Ghaemmaghami et al. 2009). However, despite its excess accumulation, quinacrine does not significantly increase the life span of prion infected mice even when drug administration is initiated shortly after inoculation (Ghaemmaghami et al. 2009).

Follow-up biochemical analyses of brain homogenates collected from drug-treated pri- 
on-infected mice provided evidence for the gradual accumulation of drug-resistant strains (Ghaemmaghami et al. 2009). Prion levels in the brains of infected mice initially diminish upon quinacrine treatment. However, this reduction is transient, and $\operatorname{PrP}^{\mathrm{Sc}}$ levels rebound as the drug is continually administered. The results suggest that chronic quinacrine treatment leads to the proliferation of resistant prion strains that survive the initial treatment. Furthermore, it was shown that $\mathrm{PrP}^{\mathrm{Sc}}$ accumulated in the brains of chronically treated mice had an altered conformational stability. The formation of quinacrine-resistant prions was also observed in infected cultured cells upon the arrest of cell division.

\section{Swainsonine}

Swainsonine is an inhibitor of Golgi $\alpha$-mannosidase II (Tulsiani et al. 1982) and inhibits the replication of specific prion strains by blocking the N-glycan processing of PrP (Li et al. 2010). Upon treating a panel of prion-infected cell lines with swainsonine, the Weissmann group observed prion-strain adaptation and resistance to the drug in different environments ( $\mathrm{Li}$ et al. 2010). This initial observation led to a number of follow-up studies exploring changes in prion-strain characteristics when subjected to different environments and treatments ( $\mathrm{Li}$ et al. 2010, 2011; Mahal et al. 2010; Browning et al. 2011; Oelschlegel and Weissmann 2013). The results of these studies led to an elegant model describing the mechanism of swainsonine resistance. A small fraction of the normal prion population is inherently swainsonine resistant, and this resistant population is selectively amplified in the presence of the drug. Once the selective pressure of the drug is removed, swainsonine-sensitive prion conformations become the dominant species once again.

\section{Aminothiazoles}

In 2010, a large cell-based screen led to the identification of a novel class of antiprion drugs with the 2-aminothiazole (AMT) chemical backbone (Ghaemmaghami et al. 2010). Follow-up struc- ture-activity relationship (SAR) studies led to the development of highly potent compounds with favorable pharmacokinetic properties (Gallardo-Godoy et al. 2011; Li et al. 2013; Silber et al. 2013). Subsequently, the in vivo efficacy of two analog compounds with the AMT backbone was evaluated in mouse models (Berry et al. 2013). Oral administration of both compounds was found to significantly extend the survival of mice infected with a number of prion strains (e.g., RML, ME7, and CWD). Importantly, significant extensions of life span were observed when drug treatment was initiated late in the course of disease (e.g., 60 days postinoculation). Despite a significant and reproducible extension of life span in these studies, AMT-treated mice eventually showed accumulation of $\operatorname{PrP}^{\mathrm{Sc}}$ in their brains and ultimately succumbed to disease. Even more disappointing, the aminothiazoles proved ineffective against human Creutzfeldt-Jakob disease prions in susceptible transgenic mice expressing human $\operatorname{PrP}^{\mathrm{C}}$.

The above studies indicate that the efficacy of AMTs is strain-specific. Importantly, in a number of detailed experiments, it was shown that the failure of AMTs is a result of induction of drug-resistant strains. Prions isolated from the brains of terminal AMT-treated scrapie-infected mice were resistant to AMTs when propagated in cell culture. The studies also revealed that selective drug pressure must be continuously maintained in vivo to preserve the resistant strain. This observation may suggest that AMT treatment results in the selection and proliferation of a resistant prion strain that is otherwise less proliferative than drugsensitive strains.

The observation that three independent antiprion drugs (quinicarine, swainsonine, and aminothiazoles) induce the formation of drug-resistant strains suggests that drug resistance may be a general confounding problem for the development of antiprion therapeutics. This highlights the urgent need for the development of cell models infected with human prions and a more target-oriented drug discovery effort to circumvent the problem of drug resistance. For example, targeting of $\mathrm{PrP}^{\mathrm{C}}$, the en- 
dogenous substrate shared by all prion strains, is more likely to identify compounds that have broad strain specificity. Additionally, more sophisticated dosing regiments involving combinations of diverse drugs and intermittent dosing may be required to avoid drug resistance.

\section{PRION STRAINS IN NON-PrP NEURODEGENERATIVE DISORDERS}

Recent findings have shown that several misfolded proteins can transmit pathogenesis in a conformationally templated manner that is analogous to PrP. Several lines of research have shown that many well-known features of prions are present in $\mathrm{A} \beta, \alpha$-synuclein, and tau aggregates (Meyer-Luehmann et al. 2006; Kordower et al. 2008; Clavaguera et al. 2009; Desplats et al. 2009; Eisele et al. 2009; Frost et al. 2009; Ren et al. 2009; Prusiner 2012). Among these shared features is the presence of conformational strains with distinct structural and phenotypic characteristics. Importantly, the presence of diverse prion strains associated with $A \beta, \alpha$-synuclein, and tau provides a molecular basis for clinical and pathological heterogeneity in $\mathrm{AD}$, PD, and other tauopathies. Below we describe recent experimental evidence for the presence of non-PrP prion strains.

\section{$A \beta$ Prion Strains}

Strong evidence for the presence of $A \beta$ strains has been obtained by infecting mice with aggregates obtained from patients with sporadic and familial (Arctic and Swedish) AD (Watts et al. 2014). A $\beta$ in patients was shown to have different conformational stabilities and patterns of plaque deposition. Inocula from each patient group resulted in different incubation periods in infected animals. Mice inoculated with the Arctic AD sample showed a pathology distinguishable from mice inoculated with the Swedish or sporadic AD samples. Specifically, the accumulation of $A \beta$ isoforms and the morphology of cerebrovascular $A \beta$ deposition differed between the two groups of inoculated mice. Remarkably, these features were maintained after a second round of passage. Additional studies showed that different aggregation profiles (e.g., $\mathrm{A} \beta_{40} / \mathrm{A} \beta_{42}$ ratio and compactness of plaques) are observed after inoculation of mice with synthetic $A \beta$ fibrils formed in vitro in the presence or absence of a detergent (Stöhr et al. 2014). These studies, and other experiments conducted in APP23 mice (Meyer-Luehmann et al. 2006; Heilbronner et al. 2013), provide strong support for the presence of distinct transmissible $\mathrm{A} \beta$ strains in $\mathrm{AD}$.

\section{Tau Prion Strains}

Strain variations have also been documented for tau aggregates. Transgenic mice infected with inocula derived from human patients afflicted with various tauopathies generated tau pathology reminiscent of the original inoculum (Clavaguera et al. 2009). Remarkably, aggregates generated after the initial transmission were able to seed endogenous mouse tau in wildtype animals. However, the serial propagation of the strain-specific properties in these mice or in new transgenic animals was not reported.

Additional support for the tau strains has come from studies in cell-culture models (Sanders et al. 2014). Cells harboring tau aggregates were classified in terms of the morphology of the generated aggregates. Two tau strains were characterized and were subsequently shown to have varying degrees of seeding efficiencies in vitro, toxicity profiles, and subcellular localizations. These strain-specific characteristics were faithfully propagated in inoculated cells. Furthermore, the specific characteristics of each tau strain were maintained in transgenic mice inoculated with each strain.

\section{$\alpha$-Synuclein Prion Strains}

A number of recent studies have shown that synthetic $\alpha$-synuclein fibrils can transmit disease in vivo, lead to cell-to-cell transmission of protein aggregates, and induce PD-like pathologies (Braak et al. 2003; Luk et al. 2012; Masuda-Suzukake et al. 2013). Support for the existence of $\alpha$-synuclein strains has come from studies by Bousset et al. (2013). This group has generated two assemblies of $\alpha$-synuclein aggre- 
gates with different propensities for binding and penetrating cells. These aggregates can propagate their structures by acting as a template for endogenous $\alpha$-synuclein. Other work by Guo et al. (2013) has characterized two distinct strains of synthetic $\alpha$-synuclein fibrils that show striking differences in the efficiency of cross-seeding tau aggregation, both in neuron cultures and in vivo. Additionally, Watts et al. (2013) have shown that brain homogenates prepared from multiple system atrophy (MSA) patients or mouse models induced disease in infected mice. The two inocula were transmitted at different rates, suggesting that the $\alpha$-synuclein aggregates constitute distinct strains. More recent evidence indicates that the MSA strains are distinct from $\mathrm{PD}$-causing prions (Prusiner et al. 2015).

\section{ACKNOWLEDGMENTS}

The authors thank the members of the Ghaemmaghami and Prusiner laboratories for helpful discussions regarding the ideas presented in this review.

\section{REFERENCES}

Adjou KT, Demaimay R, Lasmezas CI, Seman M, Deslys JP, Dormont D. 1996. Differential effects of a new amphotericin B derivative, MS-8209, on mouse BSE and scrapie: Implications for the mechanism of action of polyene antibiotics. Res Virol 147: 213-218.

Ayers JI, Schutt CR, Shikiya RA, Aguzzi A, Kincaid AE, Bartz JC. 2011. The strain-encoded relationship between PrP replication, stability and processing in neurons is predictive of the incubation period of disease. PLoS Pathog 7: e1001317.

Barret A, Tagliavini F, Forloni G, Bate C, Salmona M, Colombo L, De Luigi A, Limido L, Suardi S, Rossi G, et al. 2003. Evaluation of quinacrine treatment for prion diseases. J Virol 77: 8462-8469.

Bartz JC, Bessen RA, McKenzie D, Marsh RF, Aiken JM. 2000. Adaptation and selection of prion protein strain conformations following interspecies transmission of transmissible mink encephalopathy. J Virol 74: 55425547.

Bartz JC, Aiken JM, Bessen RA. 2004. Delay in onset of prion disease for the HY strain of transmissible mink encephalopathy as a result of prior peripheral inoculation with the replication-deficient DY strain. J Gen Virol 85: 265 273.

Baskakov IV, Breydo L. 2007. Converting the prion protein: What makes the protein infectious. Biochim Biophys Acta 1772: $692-703$.
Berry DB, Lu D, Geva M, Watts JC, Bhardwaj S, Oehler A, Renslo AR, DeArmond SJ, Prusiner SB, Giles K. 2013. Drug resistance confounding prion therapeutics. Proc Natl Acad Sci 110: E4160-E4169.

Bessen RA, Marsh RF. 1992. Biochemical and physical properties of the prion protein from two strains of the transmissible mink encephalopathy agent. J Virol 66: 20962101.

Bessen RA, Kocisko DA, Raymond GJ, Nandan S, Lansbury PT, Caughey B. 1995. Non-genetic propagation of strainspecific properties of scrapie prion protein. Nature 375: 698-700.

Bousset L, Pieri L, Ruiz-Arlandis G, Gath J, Jensen PH Habenstein B, Madiona K, Olieric V, Bockmann A, Meier $\mathrm{BH}$, et al. 2013. Structural and functional characterization of two $\alpha$-synuclein strains. Nat Commun 4: 2575.

Braak H, Del Tredici K, Rub U, de Vos RA, Jansen Steur EN, Braak E. 2003. Staging of brain pathology related to sporadic Parkinson's disease. Neurobiol Aging 24: 197 211.

Browning S, Baker CA, Smith E, Mahal SP, Herva ME, Demczyk CA, Li J, Weissmann C. 2011. Abrogation of complex glycosylation by swainsonine results in strainand cell-specific inhibition of prion replication. $J$ Biol Chem 286: 40962-40973.

Chiti F, Dobson CM. 2006. Protein misfolding, functional amyloid, and human disease. Annu Rev Biochem 75: 333-366.

Clavaguera F, Bolmont T, Crowther RA, Abramowski D, Frank S, Probst A, Fraser G, Stalder AK, Beibel M, Staufenbiel M, et al. 2009. Transmission and spreading of tauopathy in transgenic mouse brain. Nat Cell Biol 11: 909-913.

Colby DW, Prusiner SB. 2011. Prions. Cold Spring Harb Perspect Biol 3: a006833.

Colby DW, Giles K, Legname G, Wille H, Baskakov IV, DeArmond SJ, Prusiner SB. 2009. Design and construction of diverse mammalian prion strains. Proc Natl Acad Sci 106: 20417-20422.

Colby DW, Wain R, Baskakov IV, Legname G, Palmer CG, Nguyen HO, Lemus A, Cohen FE, DeArmond SJ, Prusiner SB. 2010. Protease-sensitive synthetic prions. PLoS Pathog 6: e1000736.

Collinge J, Clarke AR. 2007. A general model of prion strains and their pathogenicity. Science 318: 930-936.

Collinge J, Gorham M, Hudson F, Kennedy A, Keogh G, Pal S, Rossor M, Rudge P, Siddique D, Spyer M, et al. 2009. Safety and efficacy of quinacrine in human prion disease (PRION-1 study): A patient-preference trial. Lancet Neurol 8: 334-344.

Collins SJ, Lewis V, Brazier M, Hill AF, Fletcher A, Masters CL. 2002. Quinacrine does not prolong survival in a murine Creutzfeldt-Jakob disease model. Ann Neurol 52: 503-506.

Del Mar C, Greenbaum EA, Mayne L, Englander SW, Woods VL Jr. 2005. Structure and properties of $\alpha$-synuclein and other amyloids determined at the amino acid level. Proc Natl Acad Sci 102: 15477-15482.

Demaimay R, Race R, Chesebro B. 1999. Effectiveness of polyene antibiotics in treatment of transmissible spongi- 
form encephalopathy in transgenic mice expressing Syrian hamster PrP only in neurons. J Virol 73: 3511-3513.

Desplats P, Lee HJ, Bae EJ, Patrick C, Rockenstein E, Crews L, Spencer B, Masliah E, Lee SJ. 2009. Inclusion formation and neuronal cell death through neuron-to-neuron transmission of $\alpha$-synuclein. Proc Natl Acad Sci 106: 13010-13015.

Dickinson AG, Meikle VM. 1969. A comparison of some biological characteristics of the mouse-passaged scrapie agents, 22A and ME7. Genet Res 13: 213-225.

Dickinson AG, Fraser H, Meikle VM, Outram GW. 1972. Competition between different scrapie agents in mice Nat New Biol 237: 244-245.

Doh-ura K, Iwaki T, Caughey B. 2000. Lysosomotropic agents and cysteine protease inhibitors inhibit scrapieassociated prion protein accumulation. J Virol 74: $4894-$ 4897.

Doh-ura K, Ishikawa K, Murakami-Kubo I, Sasaki K, Mohri S, Race R, Iwaki T. 2004. Treatment of transmissible spongiform encephalopathy by intraventricular drug infusion in animal models. J Virol 78: 4999-5006.

Eisele YS, Bolmont T, Heikenwalder M, Langer F, Jacobson LH, Yan ZX, Roth K, Aguzzi A, Staufenbiel M, Walker LC, et al. 2009. Induction of cerebral $\beta$-amyloidosis: Intracerebral versus systemic $\mathrm{A} \beta$ inoculation. Proc Natl Acad Sci 106: 12926-12931.

Fraser H, Dickinson AG. 1973. Scrapie in mice. Agent-strain differences in the distribution and intensity of grey matter vacuolation. J Comp Pathol 83: 29-40.

Frost B, Jacks RL, Diamond MI. 2009. Propagation of tau misfolding from the outside to the inside of a cell. J Biol Chem 284: 12845-12852.

Gallardo-Godoy A, Gever J, Fife KL, Silber BM, Prusiner SB, Renslo AR. 2011. 2-Aminothiazoles as therapeutic leads for prion diseases. J Med Chem 54: 1010-1021.

Geschwind MD, Kuo AL, Wong KS, Haman A, Devereux G, Raudabaugh BJ, Johnson DY, Torres-Chae CC, Finley R, Garcia P, et al. 2013. Quinacrine treatment trial for sporadic Creutzfeldt-Jakob disease. Neurology 81: 20152023.

Ghaemmaghami S, Ahn M, Lessard P, Giles K, Legname G, DeArmond SJ, Prusiner SB. 2009. Continuous quinacrine treatment results in the formation of drug-resistant prions. PLoS Pathog 5: e1000673.

Ghaemmaghami S, May BC, Renslo AR, Prusiner SB. 2010. Discovery of 2-aminothiazoles as potent antiprion compounds. J Virol 84: 3408-3412.

Ghaemmaghami S, Watts JC, Nguyen HO, Hayashi S, DeArmond SJ, Prusiner SB. 2011. Conformational transformation and selection of synthetic prion strains. $J \mathrm{Mol}$ Biol 413: 527-542.

Ghaemmaghami S, Colby DW, Nguyen HO, Hayashi S, Oehler A, DeArmond SJ, Prusiner SB. 2013. Convergent replication of mouse synthetic prion strains. Am J Pathol 182: $866-874$.

Giles K, Glidden DV, Patel S, Korth C, Groth D, Lemus A, DeArmond SJ, Prusiner SB. 2010. Human prion strain selection in transgenic mice. Ann Neurol 68: 151-161.

Goldfarb LG, Petersen RB, Tabaton M, Brown P, LeBlanc AC, Montagna P, Cortelli P, Julien J, Vital C, Pendelbury WW, et al. 1992. Fatal familial insomnia and familial Creutz-
feldt-Jakob disease: Disease phenotype determined by a DNA polymorphism. Science 258: 806-808.

Guo JL, Covell DJ, Daniels JP, Iba M, Stieber A, Zhang B, Riddle DM, Kwong LK, Xu Y, Trojanowski JQ, et al. 2013. Distinct $\alpha$-synuclein strains differentially promote tau inclusions in neurons. Cell 154: 103-117.

Heilbronner G, Eisele YS, Langer F, Kaeser SA, Novotny R, Nagarathinam A, Aslund A, Hammarstrom P, Nilsson KP, Jucker M. 2013. Seeded strain-like transmission of $\beta$-amyloid morphotypes in APP transgenic mice. EMBO Rep 14: 1017-1022.

Kawasaki Y, Kawagoe K, Chen CJ, Teruya K, Sakasegawa Y, Doh-ura K. 2007. Orally administered amyloidophilic compound is effective in prolonging the incubation periods of animals cerebrally infected with prion diseases in a prion strain-dependent manner. J Virol 81: 1288912898.

Kimberlin RH, Walker CA. 1986. Pathogenesis of scrapie (strain 263K) in hamsters infected intracerebrally, intraperitoneally or intraocularly. J Gen Virol 67: 255-263.

Kocisko DA, Engel AL, Harbuck K, Arnold KM, Olsen EA, Raymond LD, Vilette D, Caughey B. 2005. Comparison of protease-resistant prion protein inhibitors in cell cultures infected with two strains of mouse and sheep scrapie. Neurosci Lett 388: 106-111.

Kordower JH, Chu Y, Hauser RA, Freeman TB, Olanow CW. 2008. Lewy body-like pathology in long-term embryonic nigral transplants in Parkinson's disease. Nat Med 14: 504-506.

Korth C, May BC, Cohen FE, Prusiner SB. 2001. Acridine and phenothiazine derivatives as pharmacotherapeutics for prion disease. Proc Natl Acad Sci 98: 9836-9841.

Le NT, Narkiewicz J, Aulic S, Salzano G, Tran HT, Scaini D, Moda F, Giachin G, Legname G. 2014. Synthetic prions and other human neurodegenerative proteinopathies. Virus Res 207: 25-37.

Legname G, Baskakov IV, Nguyen HO, Riesner D, Cohen FE, DeArmond SJ, Prusiner SB. 2004. Synthetic mammalian prions. Science 305: 673-676.

Legname G, Nguyen HO, Baskakov IV, Cohen FE, DeArmond SJ, Prusiner SB. 2005. Strain-specified characteristics of mouse synthetic prions. Proc Natl Acad Sci 102: $2168-2173$.

Legname G, Nguyen HO, Peretz D, Cohen FE, DeArmond SJ, Prusiner SB. 2006. Continuum of prion protein structures enciphers a multitude of prion isolate-specified phenotypes. Proc Natl Acad Sci 103: 19105-19110.

Li J, Browning S, Mahal SP, Oelschlegel AM, Weissmann C. 2010. Darwinian evolution of prions in cell culture. Science 327: 869-872.

Li J, Mahal SP, Demczyk CA, Weissmann C. 2011. Mutability of prions. EMBO Rep 12: 1243-1250.

Li Z, Silber BM, Rao S, Gever JR, Bryant C, Gallardo-Godoy A, Dolghih E, Widjaja K, Elepano M, Jacobson MP, et al. 2013. 2-Aminothiazoles with improved pharmacotherapeutic properties for treatment of prion disease. Chem Med Chem 8: 847-857.

Luk KC, Kehm V, Carroll J, Zhang B, O’Brien P, Trojanowski JQ, Lee VM. 2012. Pathological $\alpha$-synuclein transmission initiates Parkinson-like neurodegeneration in nontransgenic mice. Science 338: 949-953. 
Mahal SP, Baker CA, Demczyk CA, Smith EW, Julius C, Weissmann C. 2007. Prion strain discrimination in cell culture: The cell panel assay. Proc Natl Acad Sci 104: 20908-20913.

Mahal SP, Browning S, Li J, Suponitsky-Kroyter I, Weissmann C. 2010. Transfer of a prion strain to different hosts leads to emergence of strain variants. Proc Natl Acad Sci 107: 22653-22658.

Makarava N, Kovacs GG, Bocharova O, Savtchenko R, Alexeeva I, Budka H, Rohwer RG, Baskakov IV. 2010. Recombinant prion protein induces a new transmissible prion disease in wild-type animals. Acta Neuropathol 119: 177_ 187.

Makarava N, Kovacs GG, Savtchenko R, Alexeeva I, Budka H, Rohwer RG, Baskakov IV. 2011. Genesis of mammalian prions: From non-infectious amyloid fibrils to a transmissible prion disease. PLoS Pathog 7: e1002419.

Makarava N, Kovacs GG, Savtchenko R, Alexeeva I, Budka H, Rohwer RG, Baskakov IV. 2012. Stabilization of a prion strain of synthetic origin requires multiple serial passages. J Biol Chem 287: 30205-30214.

Masuda-Suzukake M, Nonaka T, Hosokawa M, Oikawa T, Arai T, Akiyama H, Mann DM, Hasegawa M. 2013. Prion-like spreading of pathological $\alpha$-synuclein in brain. Brain 136: 1128-1138.

May BC, Fafarman AT, Hong SB, Rogers M, Deady LW, Prusiner SB, Cohen FE. 2003. Potent inhibition of scrapie prion replication in cultured cells by bis-acridines. Proc Natl Acad Sci 100: 3416-3421.

Medori R, Tritschler HJ, LeBlanc A, Villare F, Manetto V, Chen HY, Xue R, Leal S, Montagna P, Cortelli P, et al. 1992. Fatal familial insomnia, a prion disease with a mutation at codon 178 of the prion protein gene. $N$ Engl J Med 326: 444-449.

Meyer-Luehmann M, Coomaraswamy J, Bolmont T, Kaeser S, Schaefer C, Kilger E, Neuenschwander A, Abramowski D, Frey P, Jaton AL, et al. 2006. Exogenous induction of cerebral $\beta$-amyloidogenesis is governed by agent and host. Science 313: 1781-1784.

Monari L, Chen SG, Brown P, Parchi P, Petersen RB, Mikol J, Gray F, Cortelli P, Montagna P, Ghetti B, et al. 1994. Fatal familial insomnia and familial Creutzfeldt-Jakob disease: Different prion proteins determined by a DNA polymorphism. Proc Natl Acad Sci 91: 2839-2842.

Morales R, Abid K, Soto C. 2007. The prion strain phenomenon: Molecular basis and unprecedented features. Biochim Biophys Acta 1772: 681-691.

Morales R, Callegari K, Soto C. 2015. Prion-like features of misfolded $\mathrm{A} \beta$ and tau aggregates. Virus Res 207: 106112.

Nakajima M, Yamada T, Kusuhara T, Furukawa H, Takahashi M, Yamauchi A, Kataoka Y. 2004. Results of quinacrine administration to patients with Creutzfeldt-Jakob disease. Dement Geriatr Cogn Disord 17: 158-163.

Nelson R, Sawaya MR, Balbirnie M, Madsen AO, Riekel C, Grothe R, Eisenberg D. 2005. Structure of the cross- $\beta$ spine of amyloid-like fibrils. Nature 435: 773-778.

Oelschlegel AM, Weissmann C. 2013. Acquisition of drug resistance and dependence by prions. PLoS Pathog 9: e1003158.
Pattison IH, Jones KM. 1967. The possible nature of the transmissible agent of scrapie. Vet Rec 80: 2-9.

Peretz D, Scott MR, Groth D, Williamson RA, Burton DR, Cohen FE, Prusiner SB. 2001. Strain-specified relative conformational stability of the scrapie prion protein. Protein Sci 10: 854-863.

Prusiner SB. 1982. Novel proteinaceous infectious particles cause scrapie. Science 216: 136-144.

Prusiner SB. 2001. Shattuck lecture-Neurodegenerative diseases and prions. N Engl J Med 344: 1516-1526.

Prusiner SB. 2012. Cell biology. A unifying role for prions in neurodegenerative diseases. Science 336: 1511-1513.

Prusiner SB. 2013. Biology and genetics of prions causing neurodegeneration. Annu Rev Genet 47: 601-623.

Prusiner SB, Scott M, Foster D, Pan KM, Groth D, Mirenda C, Torchia M, Yang SL, Serban D, Carlson GA, et al. 1990. Transgenetic studies implicate interactions between homologous $\mathrm{PrP}$ isoforms in scrapie prion replication. Cell 63: 673-686.

Prusiner SB, Woerman AL, Mordes DA, Watts JC, Rampersaud R, Berry DB, Patel S, Oehler A, Lowe JK, Kravitz SN, et al. 2015. Evidence for $\alpha$-synuclein prions causing multiple system atrophy in humans with parkinsonism. Proc Natl Acad Sci 112: E5308-E5317.

Ren PH, Lauckner JE, Kachirskaia I, Heuser JE, Melki R, Kopito RR. 2009. Cytoplasmic penetration and persistent infection of mammalian cells by polyglutamine aggregates. Nat Cell Biol 11: 219-225.

Safar J, Wille H, Itri V, Groth D, Serban H, Torchia M, Cohen FE, Prusiner SB. 1998. Eight prion strains have $\operatorname{PrP}^{\mathrm{Sc}}$ molecules with different conformations. Nat Med 4: $1157-1165$.

Sanders DW, Kaufman SK, DeVos SL, Sharma AM, Mirbaha H, Li A, Barker SJ, Foley AC, Thorpe JR, Serpell LC, et al. 2014. Distinct tau prion strains propagate in cells and mice and define different tauopathies. Neuron 82: 1271-1288.

Schutt CR, Bartz JC. 2008. Prion interference with multiple prion isolates. Prion 2: 61-63.

Scott M, Foster D, Mirenda C, Serban D, Coufal F, Walchli M, Torchia M, Groth D, Carlson G, DeArmond SJ, et al. 1989. Transgenic mice expressing hamster prion protein produce species-specific scrapie infectivity and amyloid plaques. Cell 59: 847-857.

Scott M, Groth D, Foster D, Torchia M, Yang SL, DeArmond SJ, Prusiner SB. 1993. Propagation of prions with artificial properties in transgenic mice expressing chimeric PrP genes. Cell 73: 979-988.

Shikiya RA, Ayers JI, Schutt CR, Kincaid AE, Bartz JC. 2010. Coinfecting prion strains compete for a limiting cellular resource. J Virol 84: 5706-5714.

Sigurdson CJ, Nilsson KP, Hornemann S, Manco G, Polymenidou M, Schwarz P, Leclerc M, Hammarstrom P, Wuthrich K, Aguzzi A. 2007. Prion strain discrimination using luminescent conjugated polymers. Nat Methods 4: 1023-1030.

Silber BM, Gever JR, Li Z, Gallardo-Godoy A, Renslo AR, Widjaja K, Irwin JJ, Rao S, Jacobson MP, Ghaemmaghami S, et al. 2013. Antiprion compounds that reduce $\mathrm{PrP}^{\mathrm{Sc}}$ levels in dividing and stationary-phase cells. Bioorg Med Chem 21: 7999-8012. 
S. Ghaemmaghami

Sim VL. 2012. Prion disease: Chemotherapeutic strategies. Infect Disord Drug Targets 12: 144-160.

Soto C, Castilla J. 2004. The controversial protein-only hypothesis of prion propagation. Nat Med 10: S63-S67.

Stohr J, Condello C, Watts JC, Bloch L, Oehler A, Nick M, DeArmond SJ, Giles K, DeGrado WF, Prusiner SB. 2014. Distinct synthetic $A \beta$ prion strains producing different amyloid deposits in bigenic mice. Proc Natl Acad Sci 111: 10329-10334.

Tanaka M, Chien P, Naber N, Cooke R, Weissman JS. 2004 Conformational variations in an infectious protein determine prion strain differences. Nature 428: 323-328.

Telling GC, Parchi P, DeArmond SJ, Cortelli P, Montagna P, Gabizon R, Mastrianni J, Lugaresi E, Gambetti P, Prusiner SB. 1996. Evidence for the conformation of the pathologic isoform of the prion protein enciphering and propagating prion diversity. Science 274: 2079-2082.

Trevitt CR, Collinge J. 2006. A systematic review of prion therapeutics in experimental models. Brain 129: 22412265.
Tulsiani DR, Harris TM, Touster O. 1982. Swainsonine inhibits the biosynthesis of complex glycoproteins by inhibition of Golgi mannosidase II. J Biol Chem 257: 79367939.

Watts JC, Giles K, Oehler A, Middleton L, Dexter DT, Gentleman SM, DeArmond SJ, Prusiner SB. 2013. Transmission of multiple system atrophy prions to transgenic mice. Proc Natl Acad Sci 110: 19555-19560.

Watts JC, Condello C, Stohr J, Oehler A, Lee J, DeArmond SJ, Lannfelt L, Ingelsson M, Giles K, Prusiner SB. 2014. Serial propagation of distinct strains of $\mathrm{A} \beta$ prions from Alzheimer's disease patients. Proc Natl Acad Sci 111: 10323-10328.

Weissmann C, Li J, Mahal SP, Browning S. 2011. Prions on the move. EMBO Rep 12: 1109-1117.

Wiltzius JJ, Landau M, Nelson R, Sawaya MR, Apostol MI, Goldschmidt L, Soriaga AB, Cascio D, Rajashankar K, Eisenberg D. 2009. Molecular mechanisms for proteinencoded inheritance. Nat Struct Mol Biol 16: 973-978. 


\section{$\&_{\mathrm{CSH}}^{\infty} \&$ Cold Spring Harbor

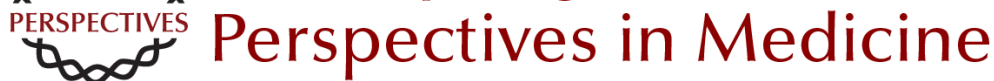

\section{Biology and Genetics of PrP Prion Strains}

Sina Ghaemmaghami

Cold Spring Harb Perspect Med 2017; doi: 10.1101/cshperspect.a026922 originally published online December 5, 2016

\section{Subject Collection Prion Diseases}

TDP-43 Prions

Takashi Nonaka and Masato Hasegawa

$\alpha$-Synuclein: Multiple System Atrophy Prions

Amanda L. Woerman, Joel C. Watts, Atsushi

Aoyagi, et al.

Genetics of Synucleinopathies

Robert L. Nussbaum

$\beta$-Amyloid Prions and the Pathobiology of

Alzheimer's Disease Joel C. Watts and Stanley B. Prusiner

Disease Mechanisms of C9ORF72 Repeat Expansions

Tania F. Gendron and Leonard Petrucelli

Chronic Traumatic Encephalopathy: Is Latency in

Symptom Onset Explained by Tau Propagation? Joshua Kriegel, Zachary Papadopoulos and Ann C. McKee

Noncerebral Amyloidoses: Aspects on Seeding,

Cross-Seeding, and Transmission

Gunilla T. Westermark, Marcus Fändrich,

Katarzyna Lundmark, et al.

Structural and Chemical Biology of Presenilin

Complexes

Douglas S. Johnson, Yue-Ming Li, Martin

Pettersson, et al.
Cell Biology and Pathophysiology of $\alpha$-Synuclein Jacqueline Burré, Manu Sharma and Thomas C. Südhof

Molecular Mechanisms of Chronic Wasting

Disease Prion Propagation Julie A. Moreno and Glenn C. Telling

Genetics of Amyotrophic Lateral Sclerosis Mehdi Ghasemi and Robert H. Brown, Jr.

The Genetics of C9orf72 Expansions Ilse Gijselinck, Marc Cruts and Christine Van Broeckhoven

Prion-Like Characteristics of

Polyglutamine-Containing Proteins Margaret M.P. Pearce and Ron R. Kopito

Therapeutic Strategies for Restoring Tau Homeostasis

Zapporah T. Young, Sue Ann Mok and Jason E. Gestwicki

Fused in Sarcoma Neuropathology in Neurodegenerative Disease Ian R.A. Mackenzie and Manuela Neumann

Experimental Models of Inherited PrP Prion Diseases Joel C. Watts and Stanley B. Prusiner

For additional articles in this collection, see http://perspectivesinmedicine.cshlp.org/cgi/collection/ 